\title{
LA ESPERANZA SOBRENATURAL COMO ELEVACIÓN DE LA LIBERTAD PERSONAL SEGÚN L. POLO
}

Fecha de recepción: 25 de mayo de 2018

Fecha de aceptación y versión final: 21 de septiembre de 2018

RESUMEN: En este trabajo se estudia la índole de la esperanza sobrenatural según el pensamiento de L. Polo. Se indica que se añade a la libertad personal del acto de ser humano (no a la inteligencia o a la voluntad); que requiere de la fe y de la caridad, que mira al futuro metahistórico y es susceptible de incremento hasta su consumación.

PALABRAS CLAVE: esperanza sobrenatural; L. Polo; acto de ser; libertad personal.

\section{Supernatural Hope as Elevation of Personal Freedom According to L. Polo}

ABSTRACT: In this work the nature of the supernatural hope according to the thought of L. Polo is studied. It is indicated that it is added to the personal freedom of the human act of being (not to the intelligence or to the will); which requires faith and charity, which looks to the meta-historical future and is susceptible to increase until its consummation.

KEY WORDS: supernatural hope; L. Polo; act of being; personal freedom.

\footnotetext{
" Universidad de Navarra: jfselles@unav.es; ORCID: https://orcid.org/0000-0003$1839-1276$ 


\section{PLANTEAMIENTO}

Leonardo Polo distinguió dos tipos de esperanza, la natural y la sobrenatural. A la primera le dedicó el artículo titulado "La esperanza" ${ }^{1}$ que luego entró a formar parte de uno de sus libros, La esencia del hombre ${ }^{2}$. A la segunda le prestó atención sobre todo en dos de sus publicaciones: La persona humana y su crecimiento ${ }^{3}$ y su obra póstuma Epistemología, creación y divinidad ${ }^{4}$.

De la primera, de la esperanza natural, cabe brevemente reseñar que Polo distingue en ella -reuniendo los pasajes mencionados- estos nueve componentes: 1) el sujeto libre que desea realizar un encargo; 2) el optimismo que tal sujeto debe albergar para llevarlo a cabo; 3) el futuro para alcanzar la meta; 4) la tarea mediante la cual alcanzará el objetivo; 5) los recursos de que dispone; 6) la ayuda de los demás con que puede contar; 7) quien encarga la tarea, 8) el beneficiario de la tarea, y 9) el riesgo o los factores de inseguridad con los que se puede encontrar, es decir, lo adverso. Para exponerlo de modo sencillo Polo recurría al paradigmático cuento de Caperucita Roja, a la novela Don Quijote de la Mancha ${ }^{5}$, o también a las figuras de Ulises y Abraham ${ }^{6}$, ejemplos en los que se advierten fácilmente estos componentes. Cabría pensar que la esperanza natural cuenta con un límite inexorable que no puede trascender, la muerte, pero eso solo sucede si se la refiere al espacio ${ }^{7}$, porque si se la refiere al tiempo, trasciende dicho límite, ya que el alma humana es inmortal ${ }^{8}$.

1 Cfr. Leonardo Polo, "La esperanza”, Scripta Theologica 30 (1998): 157-164.

2 Cfr. Leonardo Polo, Obras Completas, vol. 23, La esencia del hombre (Pamplona: Eunsa, 2015), 67-79.

3 Cfr. Leonardo Polo, Obras Completas, vol. 13, La persona humana y su crecimiento (Pamplona: Eunsa, 2015), 71-74.

4 Cfr. Leonardo Polo, Obras Completas, vol. 27, Epistemología, creación y divinidad (Pamplona: Eunsa, 2015), 111-119.

5 Cfr. Leonardo Polo, Obras Completas, vol. 10, Quién es el hombre (Pamplona: Eunsa, 2015), 206.

6 Cfr. Leonardo Polo, Epistemología, 116.

7 «Por lo que se refiere a la esperanza humana, es tergiversada si se vierte en el espacio: la esperanza es la fuerza del homo viator; pero la esperanza dirigida al espacio tiene como límite a la muerte, es incapaz de traspasarla». Leonardo Polo, Obras Completas, vol. 25, Filosofía y economía (Pamplona: Eunsa, 2015), 45.

8 «La alegría y la esperanza consisten en que uno supera a la muerte. Y la supera porque es un espíritu [...]. La inmortalidad es nuestra esperanza; porque somos espíritus existe la esperanza. Sabemos, y eso es esperar, que no todo acaba con la muerte, 
De la segunda, de la esperanza sobrenatural, hay que decir que no debe prescindir de los anteriores componentes, solo que en esta todos ellos cobran un nuevo realce, pues quien encarga la tarea es Dios, la labor que encarga a cada quien en esta vida es distinta, pues el encargo que da se llama "vocación», no habiendo dos iguales. Además, es Dios mismo el que ayuda a la persona libre a cumplir la obra dotándola de una ayuda sobrenatural: precisamente la virtud de la esperanza, en la que centraremos seguidamente la atención siguiendo el pensamiento de Polo.

\section{LOS TRASCENDENTALES PERSONALES Y LAS VIRTUDES TEOLOGALES}

La esperanza es engendrada por la confianza; en cristiano, por la fe. Por eso la esperanza hay que estudiarla tras tratar de la fe, porque «la seguridad de la esperanza depende de la fe; espero porque creo, pero no cabe sentar el postulado de que llegaré a Dios necesariamente. Dios no puede fallarme, pero yo sí. La esperanza no es "infalible" »". Lo que es infalible es la temática objetiva que se cree por fe sobrenatural ${ }^{10}$, pero ni siquiera la fe tomada «subjetivamente» es infalible, pues se puede perder culpablemente. A su vez, la esperanza y la fe dependen de la caridad y también esta se puede perder por culpa propia, seguramente más fácil que aquellas. Además, esa pérdida nos separa más de Dios, porque Dios es Amor ${ }^{11}$, pero no es esperanza ni fe.

Esperanza, fe y caridad. Este orden de dependencia indica que la caridad es superior a la fe y, esta, a la esperanza. Dicho orden se corresponde con el orden natural de los trascendentales personales descubiertos en el acto de ser personal por Leonardo Polo, pues este revela que el superior de ellos es el amor personal, seguido del conocer personal y luego

aunque la muerte sea un acabamiento sin más. Es el término de estar en el mundo». Leonardo Polo, La persona como centro de la enfermería, pro manuscripto, 5.

9 Leonardo Polo, "La persona humana", 83. En otro lugar Polo escribe: «La íntima unión entre la fe y la esperanza es advertida en la epístola a los Hebreos: la fe es la sustancia de las cosas que se esperan», Epistemología, 266.

10 «Para el cristiano la infalibilidad sólo se predica de la fe», Leonardo Polo, $\mathrm{La}$ persona humana, 83.

11 Cfr. 1 Jn 4,8 . 
por la coexistencia libre. Por eso, la caridad, que eleva al amor personal, atrae al conocer del intelecto personal, el cual es elevado por la fe, intelecto que marca el norte o sentido de la libertad personal, la cual es elevada por la esperanza.

La esperanza se vincula a la libertad ${ }^{12}$. Si la verdad que se conoce por el intelecto personal hace libres, la elevación de la verdad personal, la fe sobrenatural, rinde esperanzados. Y si el amor, que trasciende todo conocimiento, atrae a este o tira de él, también vincula a la libertad, hasta el punto de que no se desea tener otra que la de $\operatorname{amar}^{13}$.

La relación entre la libertad, el conocer y el amar se suele establecer en la filosofía tradicional en el ámbito de la inteligencia y de la voluntad, las potencias inmateriales, las superiores o, si se quiere, no en el ámbito trascendental o del «acto de ser» personal humano, sino en el predicamental o de la «esencia» del hombre. Lo trascendental es nativamente activo, mientras que tales potencias son constitutivamente pasivas. A nivel de estas se habla, por ejemplo, de «deseo de saber», que es la descripción ancestral de la filosofía. También de la esperanza como de una «virtud» de la voluntad, indicando con ello el crecimiento de dicha facultad en orden al bien sumo, su fin último. Aunque Polo alguna vez trate de estos asuntos con tales coordenadas clásicas ${ }^{14}$, lo que en rigor añade a tal planteamiento es emplazar tales realidades humanas en el plano de la persona, del acto radical, y abrirlas a su elevación sobrenatural. Por eso incluso en esos pasajes matiza que «hay una libertad más alta que la esperanza de vivir más con la innovación en el hombre mismo; ese más sería el ser para otro, ser libre para otro. Eso es una más alta libertad y esa es la libertad intersubjetiva $»^{15}$.

12 «Forma parte de la libertad otra cosa muy importante: la esperanza. La esperanza es tanto antecedente como consecuente de la libertad. La libertad se vive en esperanza. Uno espera ser libre, y cuando es libre espera más. Uno espera más verdad» Leonardo Polo, Quién es el hombre, 209.

13 «Sin el amor de esperanza la vida del espíritu se destensa» Leonardo Polo, Obras Completas, vol. 11, Ética: hacia una versión moderna de temas clásicos (Pamplona: Eunsa, 2018), 265.

${ }_{14}$ Por ejemplo, escribe: «La esperanza no es sólo la contemplación de algo, la esperanza está en el orden del crecer, es constitutiva del ser humano. Vivir en acto es vivir actualmente, pero en orden a la virtud vivir es con la esperanza de vivir más» Leonardo Polo, Obras Completas, vol. 19, Persona y libertad (Pamplona: Eunsa, 2017), 222.

15 Leonardo Polo, Persona y libertad, 224. 
Lo que se quiere decir con lo que precede es que las virtudes llamadas «teologales», de las que habla la doctrina cristiana, no elevan directamente la "naturaleza» o "esencia» humanas, sino el "acto de ser» personal, o sea, las dimensiones íntimas de cada quién. Esta tesis es netamente poliana: «las virtudes infusas pertenecen a la co-existencia» ${ }^{16}$. «Coexistencia», según él, equivale a "persona», no a «naturaleza» corpórea humana, o a las dimensiones de la «esencia del hombre», a saber: la inteligencia, la voluntad y el yo, porque ninguna de estas es coexistente, sino simplemente existentes. Con ello no se quiere decir que tales realidades humanas no estén abiertas a la alteridad, ya que no se explican sin ella, sino que no son «actos de ser» o «personas». En efecto, la inteligencia y la voluntad no son la persona, sino de la persona; y así las demás potencias, hábitos y funciones humanas. Tampoco el «yo» es la «persona» sino de ella: «el yo no es idéntico con la persona humana, sino el ápice de la esencia del hombre en tanto que depende de la persona ${ }^{17}$.

Polo designa a la "coexistencia» con el adverbio además, el cual denota crecimiento y dirección hacia un destino. Por eso «el carácter de además indica la intensidad de un existir centrado en la esperanza. La esperanza [...] aquí se emplea para expresar la intensidad de la búsqueda trascendente, cuyo equilibrio debe llamarse culminación ${ }^{18}$. Tal esperanza es natural y está vinculada a la coexistencia y a la libertad personales. Con mayor concreción: «En la esencia humana su perfección final es habitual y, en el acto de ser humano creado, a la perfección la llamo carácter de además, que está vinculado directamente a la esperanza, entendida ontológicamente» ${ }^{19}$. Pues bien, como veremos seguidamente, la esperanza sobrenatural eleva esa esperanza natural.

Lo que precede supone una noción de persona ciertamente distinta de la clásica, o sea, de la célebre debida a Boecio (la menos solvente de las 6 que formuló), pues si la persona es el acto de ser del hombre, no puede ser «sustancia» (compuesto hilemórfico) o «naturaleza» (como principio de operaciones), porque ambas denotan potencialidad. Esas denominaciones describen la unión entre cuerpo y alma humana. Pero

16 Leonardo Polo, Obras Completas, vol. 15, Antropología trascendental (Pamplona: Eunsa, 2015), 455, nota 153.

17 Leonardo Polo, Antropología trascendental, 184.

18 Leonardo Polo, Obras Completas, vol. 17, Nietzsche como pensador de dualidades (Pamplona: Eunsa, 2018), 202.

19 Leonardo Polo, Epistemología, 255. 
Polo distingue realmente la persona de su cuerpo y alma. Aunque perfilar su noción de persona daría para otro trabajo, aquí nos limitaremos a indicar de modo breve y seguidamente qué no es la persona y qué es según el autor. Así, tras esta síntesis, se notará más fácilmente que, tal como él entiende esta noción, es estrictamente atribuible a todas las personas, sean estas humanas, angélicas o divinas.

a) Para Leonardo Polo, la persona humana no es: 1) ni el alma humana, ni la esencia del hombre, ni el yo, pues el alma vivifica el cuerpo y a las potencias inmateriales, y la esencia del hombre equivale al perfeccionamiento de dichas potencias más al desarrollo de la personalidad, la cual radica en el «yo»; pero ninguna persona se reduce a su inteligencia y a su voluntad y tampoco equivale a su personalidad. 2) La persona no es la unión de alma y cuerpo, porque este es potencial, y el alma, siendo activa, constituye la esencia del hombre, sobre todo cuando la persona la perfecciona; pero la esencia del hombre no es el acto de ser: distinción real. 3) No es una potencia o facultad humana, ni el conjunto de ellas, por lo indicado acerca de la potencialidad. 4) Tampoco es un acto como operación inmanente o como un hábito (adquirido o innato), ni el conjunto de todos ellos, porque el acto de ser es irreductible a ellos. 5) No es reflexiva como causa sui, porque esa noción es contradictoria. 6) No es espacio y tiempo físicos, porque estos afectan al cuerpo, no al alma, y menos aún al acto de ser personal. 7) No es el cuerpo humano, por lo indicado. Por eso se sigue siendo persona tras la muerte. 8) No es el «todo» de lo arriba indicado -alma, cuerpo, facultades, actos, hábitos, virtudes, cuerpo-. Y menos aún es el «todo» de lo precedente más todas las manifestaciones derivadas de dichas dimensiones, porque el acto de ser no es una suma o composición. 9) No es ni universal ni particular, porque estas nociones designan o bien asuntos físicos o bien mentales, pero la persona trasciende lo físico y lo mental, ya que es de orden trascendental (por eso se habla de «trascendentales personales», perfecciones que la describen como acto de ser).

b) Para Leonardo Polo, la persona humana es: 1) el acto de ser del hombre, si se acepta en antropología la distinción real tomista essentia-actus essendi. 2) Es el núcleo del saber y el núcleo de lo voluntario, pues la inteligencia y la voluntad, como potencias pasivas que nativamente son, no podrían ser activadas de no existir un acto nativo previo y superior a ellas, además de perfectamente coherente con ellas, es decir, cognoscente y amante. 3) Es además; gramaticalmente la persona no es un pronombre, 
sino un adverbio, que significa al menos dos cosas: a) una, que la persona es además del universo físico y además de la esencia del hombre; por tanto, además de su pensar, de su querer y de su cuerpo; b) otra, que esa «ademaseidad» es creciente y elevable de cara a Dios. 4) Es coexistencia con, libertad personal, conocer personal (intelecto personal) y amar donal, es decir, equivale a las características íntimas del acto de ser personal, que Polo llama trascendentales personales. 5) Es intimidad abierta, pues lo propio de la persona no es la inmanencia, sino la intimidad, la cual es abierta interiormente y hacia la trascendencia. 6) Es el viviente, no su vida, la cual es el alma humana que otorga vida a la corporeidad. 7) Es relación trascendental, es decir, no relación sustancial ni accidental, pues es una relación del acto de ser personal, que ni es sustancia ni accidente. 8) Es novedosa e irrepetible, lo cual indica que cada persona es distinta (una coexistencia libre distinta, un conocer y amar personales distintos); en cambio, la naturaleza corpórea humana es común a la humanidad, aunque con matices diversos, y la esencia humana tiene nativamente elementos comunes a todos los hombres (la inteligencia y voluntad como potencias pasivas), aunque al activarla la persona adquiere distinciones esenciales. 9) Es filial con Dios, pues la persona humana es búsqueda de aceptación filial. Nativamente se trata de la filiación natural, no de la sobrenatural, la cual es la elevación por parte de Dios de la precedente.

Dicho esto se puede entender mejor lo que sigue, a saber, por qué Polo considera que la esperanza sobrenatural es la elevación de la libertad que radica nativamente en el acto de ser personal humano, no la elevación, por ejemplo, de la voluntad, la cual es nativamente potencia pasiva.

\section{LA ESPERANZA COMO ELEVACIÓN DE LA COEXISTENCIA LIBRE}

Si la persona humana no «es» sino que «es-con», siendo el «con» tan relevante como el «es», porque es lo distintivo del acto de ser personal humano, la persona humana no puede culminar desde sí. Según esto, la esperanza sobrenatural es la elevación del "con» humano referente al Dios revelado, y la culminación es la unión definitiva del ser humano con él. La esperanza natural anhela la culminación en el Dios que el intelecto personal alcanza a saber de él de modo natural, y es claro que tal anhelo no se puede lograr en solitario: «la esperanza de culminación de la persona $[\ldots]$ no puede ser lograda solo por la persona, y a eso he 
llamado límite ontológico $»^{20}$. Y como el Cielo, la vida íntima con Dios, no es un requerimiento de la persona humana, sino el mayor regalo posible de Dios al hombre, para anhelarlo, la esperanza natural es elevada por la sobrenatural. Pero como el Cielo es el «será» de nuestro acto de ser, al que estamos llamados y todavía no somos o no hemos llegado a ser, nos encaminamos a él gracias a la esperanza sobrenatural, aunque su logro no dependa de nosotros ${ }^{21}$. Lo barruntamos con la fe; nos encaminamos a ese destino mediante la esperanza y lo rozamos con la caridad, pues esta guarda más afinidad con él.

Por eso, la caridad no solo anima la fe sino que engendra y da alas a la esperanza: «La esperanza se vincula al amor, de él arranca y a él se encamina [...] La esperanza se funda en la reciprocidad amorosa y se dirige a fomentarla por encima de las veleidades humanas [...] La esperanza se funda en el amor e intenta corresponder ${ }^{22}$. El amor personal humano no es ciego, porque está unido al conocer personal, y no es necesitante, porque está unido a la libertad. Como esta es elevada por la esperanza, «también el amor del hombre es amor de esperanza» ${ }^{23}$. Este amor es distintivo del cristianismo ${ }^{24}$, porque este, más que una religión, es una revelación sobrenatural ${ }^{25}$ en la que Dios otorga, a la persona a quien se

\footnotetext{
20 Leonardo Polo, Nietzsche, 246.

21 «Como término del amor divino se expresa con clamores o gemidos inefables.
} Dicha expresión está llena de la nostalgia, de la esperanza de lo que tiene que ser. ¿A dónde va la expresión, a qué acude, dónde se consuma? La expresión se consuma en la conversación: conversatio nostra in coelis est. Después de las decisiones no están sólo las consecuencias, sino la esperanza de ser dicho desde lo alto, por el amor que juzga". Leonardo Polo, Obras Completas, vol. 22, Lecciones de psicología clásica (Pamplona: Eunsa, 2015), 313.

22 Leonardo Polo, Obras Completas, vol. 13, La originalidad de la concepción cristiana de la existencia (Pamplona: Eunsa, 2015), 247-251. En el texto se añade: «Estas consideraciones enmarcan los temas centrales de la existencia y de la persona humana $[\ldots]$ ¿Qué significa la esperanza humana tal como el cristianismo la formula?, es decir, ¿qué es la esperanza en el orden del amor? También se puede expresar así: ¿Cuál es la tarea de mi vida? ¿Qué es mi vida como tarea? La tarea es una dilatación de la libertad desde la intimidad personal».

23 Leonardo Polo, Antropología trascendental, 191, nota 1.

24 «La eficacia restauradora del auténtico sentido creatural del hombre se encuentra en el amor cristiano como amor de esperanza». Leonardo Polo, El hombre en la historia, Cuadernos de Anuario Filosófico 207 (Pamplona: Servicio de Publicaciones de la Universidad de Navarra, 2008), 86.

25 «El cristianismo no es una religión. Porque ¿qué es una religión? Es la consideración de una relación en que el término a quo es el hombre y el término ad quem 
manifiesta, una elevación sobrenatural para que capte el sobrenatural mensaje divino, lo anhele y lo ame.

«La cumbre de la esperanza es la correspondencia: amar como uno es amado» ${ }^{26}$, como la cumbre del conocer es conocer como uno es conocido. Por tanto, la esperanza nace del amor en quien ama y busca el amor, es decir, la aceptación de aquel a quien ama: «nótese que la esperanza es inherente al buscar ${ }^{27}$, y si se busca es porque se conoce, y se anhela conocer y se conoce en la medida en que se ama. El amor personal tiene, según L. Polo, dos dimensiones trascendentales, el aceptar y el dar, siendo la primera superior a la segunda. Pues bien, «la esperanza cristiana es la búsqueda de aceptación y respuesta, es decir, de encontrar al semejante ${ }^{28}$, mejor, a quien uno se asemeja o de quien es imagen, porque solo mirándole a él conozco que mi imagen es imagen suya y hasta qué punto lo es. Ese es Dios, y él también da para que el hombre acepte, de modo que, si no lo hace, peca ${ }^{29}$.

Pero, según Polo, el amor personal exige otra dimensión que no es trascendental o distintiva del acto de ser humano, sino manifestativa o de la esencia del hombre, pues debe manifestarse en obras, las cuales pueden ser inmateriales o corporales. Las primeras se ejercen en la esencia del hombre (p. ej. descubrimientos de la inteligencia); las segundas, en la naturaleza humana (p. ej. trabajo). En efecto, el aceptar y el dar requieren la mediación del don. También a través del don se capta que el amor personal humano es esperanzado y con sentido, pues se espera que Dios acepte nuestras obras. Aunque los demás no sepan de ellas y a uno mismo se le olviden, las obras tienen valor, primero, en la medida en que pueden ser aceptadas por Dios; por eso las que no pueden

el universo. El cristianismo no es eso. El cristianismo es revelación». Leonardo Polo, Persona y libertad, 156.

26 Leonardo Polo, Antropología trascendental, 191, nota 1.

27 Leonardo Polo, Antropología trascendental, 234.

28 Leonardo Polo, Antropología trascendental, 252. En otro lugar lo explica de este modo: «La esperanza es la laguna entre el dar y el aceptar, pero que todavía conserva que se puede mantener el dar a pesar que hay una laguna o una diferencia temporal». Conversaciones en Torreblanca (Colombia, agosto de 1997 pro manuscripto), 191.

29 «Si el hombre no acepta o tarda es que está pecando y entonces tiene que ser perdonado. Es una especie de esperanza divina en el hombre [...] Se podría hablar, aunque sea de un modo analógico, de una esperanza divina en el hombre. El Antiguo Testamento está lleno de esa idea. El diálogo de Moisés con el Señor cuando el pueblo no le acepta y quiere ser idólatra; es el gran profeta de la esperanza. Oseas también es el gran profeta de la esperanza». Leonardo Polo, Conversaciones en Torreblanca, 191. 
ser aceptadas por él carecen de sentido y hay que evitarlas; segundo, en la medida en que estén atravesadas de sentido personal propio, ya que cada quién es un «invento» divino distinto, y por eso las obras son aceptables por el ser divino, el cual acepta a cada quién a través de sus obras.

Polo escribe: "con la noción de querer-querer-más procuro describir el amor de esperanza ${ }^{30}$. Sin embargo, tal vez esa descripción sea reductiva por ceñirse en exclusiva al refuerzo que el querer de la sindéresis (recuérdese que este hábito innato activa y refuerza a la razón práctica $\mathrm{y}$ al querer de la voluntad) añade al de la voluntad, pues en rigor, se trata de dos quereres, no de dos amores, y ni siquiera de uno solo, ya que amar no equivale a querer, y ni la sindéresis ni la voluntad aman, sino que quieren, porque no son la persona, sino de ella. En efecto, el querer es, o bien de la sindéresis, o bien de voluntad. El primer querer de la expresión poliana «querer querer» es propio de la sindéresis; el segundo, de la voluntad. Por tanto, para describir el amor de esperanza, tal vez sea mejor decir algo así como «aceptación de definitiva y completa correspondencia personal», puesto que aceptar es personal.

\section{EL INCREMENTO DE LA ESPERANZA SOBRENATURAL}

Se está esperanzado porque no se ha alcanzado la entera correspondencia del amor que se busca, pues «el amor del hombre es un amor de esperanza: mira a la correspondencia, es decir, a una aceptación más donal que el amor humano ${ }^{31}$. De modo que los supuestos amores autosuficientes no son personales, porque el amor no se consuma en sí mismo, ya que el «entre» personas del amor es constitutivo suyo. No puede ser de otro modo si el amor es personal, porque la persona es reciprocidad. La esperanza humana está animada por la caridad y, asimismo, como no cabe amar sin libertad, «en el amor humano redunda la esperanza personal de que el amor no se destruya por falta de correspondencia» ${ }^{32}$. El crecer de la esperanza apunta al amor, y tal crecimiento que espera consumación solo se lo puede otorgar la definitiva correspondencia amorosa: «el más es la esperanza de no quedar confundido eternamente»33.

\footnotetext{
$30 \quad$ Leonardo Polo, Antropología trascendental, 420 nota 81.

31 Leonardo Polo, Antropología trascendental, 427.

32 Leonardo Polo, Antropología trascendental, 509.

33 Leonardo Polo, Antropología trascendental, 514.
} 
La persona es libertad -no se trata de que tenga libertad-, y como la esperanza sobrenatural es la elevación de la libertad personal (no de la libertad de la inteligencia y de la voluntad -el libre albedrío, según denominación medieval-, conviene indicar que la persona elevada es esperanza sobrenatural -no que la tenga-. «Desde aquí cabe sostener que el constitutivo último de la existencia elevada precisivamente considerada es la esperanza ${ }^{34}$, o si se quiere, que la persona humana "se concreta, in via, en vivir-yo como esperanza [...]. El final humano no es un término sino una culminación en el amor-don. Respecto de este final es la vida humana esperanza ${ }^{35}$. Como se puede advertir, es manifiesto que esa esperanza es -como todo lo vivo- creciente, no fija, o decreciente, si uno reniega libremente de la elevación ${ }^{36}$.

Lo anterior indica que la persona es acto, el cual es creciente de cara y con ayuda del Acto; o sea, que no es una potencia susceptible de desarrollo, pues es perfección nativa creciente y elevable. Se ha hecho hincapié en que la persona humana es el acto de ser del hombre, el cual excluye por definición la potencialidad, pues se trata de un acto creciente que pasa de acto a más acto y que, además, puede ser elevado como acto por Dios. Por tanto, aunque se entienda el significado de la expresión clásica "potencia obediencial» con que la tradición teológica habla de la persona, en sentido estricto esa expresión requiere de mayor precisión, puesto que el acto de ser personal humano carece de potencia. En efecto, este modo de hablar se puede predicar de las dimensiones potenciales de la esencia del hombre (la inteligencia y la voluntad), pero no del «acto de ser» personal humano. La elevación a este nivel es designada por Polo como nueva creación: «Atendiendo a la esperanza personal [...] es preferible hablar de nueva creación, porque la luz transparente es un acto creado concorde con la iniciativa divina ${ }^{37}$. La trasparencia personal es nativamente luz y es creciente, no es solo una diafanidad

\footnotetext{
34 Leonardo Polo, La persona humana, 164.
}

35 Leonardo Polo, La persona humana, 173-174.

36 "La característica inseguridad de la esperanza no debe entenderse como indicio de esterilidad de la actividad existencial humana, pues el futuro se afronta de acuerdo con el puro sobrar, que es indicado por el carácter de además, que no es simplemente un crecimiento, sino un insistir sin cansancio. En efecto, el no culminar de suyo, que es propio de la esperanza existencial, es incompatible con el desistir». Leonardo Polo, Epistemología, 216.

37 Leonardo Polo, Antropología trascendental, 356. 
susceptible de ser iluminada. En suma, la persona no está en potencia de ser acto, sino que es «acto de ser», es creciente en orden a Dios y puede ser elevada por él. En consecuencia, con la elevación sobrenatural, la persona humana como esperanza es activa, aunque no haya alcanzado su culmen de actividad: «en rigor, el aún-no ser del hombre elevado es una realidad que ha de alcanzar su ser definitivo [...]. De este ser definitivo no es el hombre in via potencia, sino esperanza [...]. La esperanza vibra, por tanto, en lo más nuclear de lo humano, constituyéndolo en relación a Dios» ${ }^{38}$. La persona humana está tan íntimamente unida al Acto -a menos que libremente se separe de él- que cabe designarla como un acto-con-el Acto.

Tal vez la descripción precedente sea un tanto atrevida y quepa matizarla, pero con ella se quiere indicar que la persona humana «es con» Dios, y que sin él carece de sentido. Carecer de sentido equivale a perder el sentido personal, o lo que es lo mismo, perder el ser personal. Como se ha adelantado, de la expresión «ser-con» el «con» no es ajeno o exterior al «es», sino que es el carácter mismo de tal «ser», lo distintivo del ser que se llama persona. Retirarle a la persona tal apertura es liquidarla como persona. El problema es que la réplica de esa apertura personal humana se barrunta, pero no se clarifica ni se logra definitivamente en esta vida.

La unión de la persona humana a la divina in via es libremente progresiva y lleva a que la primera se divinice paulatinamente: «se va llegando a la desnudez personal -escribe Polo-. En este proceso, el agente principal es el Espíritu Santo [...], bajo cuya acción el hombre se hace esperanza pura, acrisolada, madura con la madurez jugosa de la libertad profunda» ${ }^{39}$. Es otro modo de decir que la persona humana realmente se «endiosa». No en vano, pues, Cristo recordó ese pasaje de la Escritura en el que se dice: "Yo os digo: sois dioses» ${ }^{40}$. De otro modo: el in crescendo propio de la esperanza equivale al endiosamiento.

38 Leonardo Polo, La persona humana, 174.

39 Leonardo Polo, La persona humana, 177.

40 «No está escrito en vuestra Ley: Yo dije: 'Sois dioses'?» Jn 10, 34. La referencia a la Ley dice así: "Yo os digo: 'Vosotros sois dioses, todos vosotros, hijos del Altísimo'», Salmo, 82, 6. 


\section{APERTURA AL FUTURO METAHISTÓRICO}

Más que hablar de alcanzar a Dios, es pertinente decir que aquí Dios nos alcanza manifestándose como es, y que nos alcanzará de tal manera que no nos deje. Esto último en cristiano se llama «perseverancia final, gracia no merecida $»^{41}$, regalo divino. Al respecto Polo solía indicar que respecto de Dios alguien puede decir: «en esta vida yo te acompañaré por donde quieras, pero el que me lleves definitivamente después depende de ti». Esto implica confianza por parte de la persona humana, pero no asegura el Cielo. Y es precisamente esa confianza la que, a pesar de los pesares, ayuda a no desistir, pues debido a la debilidad de la naturaleza corpórea humana, a los avatares de la vida y a las propias debilidades personales y esenciales, "hay una tendencia a desistir; pero si se tiene suficiente esperanza y se sabe que Dios siempre escucha... entonces, se insiste $»^{42}$.

Esto denota que la esperanza personal no se comprende sin futuro, pero se trata un futuro peculiar, porque no es el temporal, es decir, no es el susceptible de volverse pasado. A los futuros temporales que pueden devenir pasados Polo los llama «desfuturizables». En cambio, al que no es susceptible de volverse pasado lo llama «no desfuturizable». Pues bien, «la esperanza cristiana... comporta un sobrar. Pero el sobrar de la esperanza se mantiene más allá del tiempo» ${ }^{43}$. Si la esperanza sobra respecto del tiempo histórico, es que no es una realidad temporal. «Por tanto, el hombre sólo puede salir en el tiempo del tiempo mediante la esperanza... la esperanza enlaza con el extremo del tiempo: es un 'sobrar' que el tiempo no gasta» ${ }^{44}$.

Si la esperanza eleva a la libertad personal, y esta cambia el rumbo de los acontecimientos históricos, esto indica que la libertad personal

41 Leonardo Polo, "Epistemología”, 254. En otro lugar indica: «La posibilidad de culminar se corresponde estrechamente con la profundidad de la esperanza personal. Una esperanza cuyo cumplimiento depende de la aquiescencia divina -de lo que se llama don de la perseverancia final- está separada evidentemente de su culminación». Nietzsche, 225).

42 Leonardo Polo, Ayudar a crecer. Cuestiones de filosofía de la educación (Pamplona: Eunsa, 2006), 163. Tal insistencia equivale a perseverar en la oración: «Saber rezar con entereza es un hábito, es poner la fe, la esperanza y la caridad en marcha, es crecer en virtudes». 204. Cursivas en el original.

43 Leonardo Polo, La persona humana, 72.

44 Leonardo Polo, La persona humana, 72. 
no es temporal ${ }^{45}$ y que, elevada por la esperanza, que tampoco es temporal, los puede cambiar en mayor medida ${ }^{46}$. Con todo, no es esto lo radical de la esperanza, sino «sobrar» respecto del tiempo histórico, o si se quiere, apuntar al más allá de él. El cristiano sabe que el tiempo es criatura y que, además de comienzo, tiene término. Pero la esperanza salta el tiempo. Por tanto, apunta a lo que carece de comienzo y de término, y eso, solo caracteriza a Dios. Por tanto, la persona esperanzada no se puede ver como una realidad temporal, sino como una novedad pura respecto del cosmos, que más que para corresponderse con él, está diseñada para corresponderse con el ser divino. Dicho en cristiano: «ese más allá es Cristo Crucificado y Resucitado, que vivifica al cristiano: vita vestra est abscondita cum Christo in Deo, que ha de venir en su Gloria» ${ }^{47}$.

De lo que precede deriva una conclusión válida para la metafísica (con el que se rectifica, entre otras, la posición heidegeriana): el tiempo no es el telar del ser, al menos del ser personal humano, porque la «esperanza va más allá del tiempo en tanto que la libertad enlaza con su extremo ${ }^{48}$. Pero, bien mirado, es una tesis valida, más que para la metafísica, para la antropología trascendental, pues el hombre -frente a las tesis de Marx, Nietzsche, Freud, Heidegger o Sartre- no es tiempo. Si es tesis aristotélica que "conocer el tiempo no es tiempo", hay que añadir que es tesis cristiana que «esperar sobrenaturalmente es supratemporal», es decir, la esperanza sobrenatural ratifica que la persona humana no es tiempo, porque «el sobrar de cada soy respecto de la temporalidad se abre en la esperanza ${ }^{49}$. Si el futuro temporal pesa en el hombre más que el pasado y el presente, hasta el punto de que cabe describir al hombre como un ser de proyectos, el futuro metahistórico -la parusía- pesa en el acto de ser personal al ser elevado hasta describirlo; por eso «el cris-

45 «La libertad humana es un factor supertemporal que incide en el tiempo introduciendo novedades que el tiempo no puede traer por sí solo». Leonardo Polo, La persona humana, 74.

46 «Según la esperanza se ejerce la libertad respecto del tiempo. Esa es la libertad sin petulancia porque la esperanza no es desencarnada: no desarraiga al hombre del tiempo, sino que es el "sobrar" de un ser temporal que no es un trozo de tiempo. La esperanza orienta hacia más allá del tiempo». Leonardo Polo, La persona humana, 72 .

47 Leonardo Polo, La persona humana, 71.

48 Leonardo Polo, La persona humana, 73.

49 Leonardo Polo, La persona humana, 73. 
tianismo se tensa hacia delante porque no renuncia a la esperanza $»^{50}$. En suma, «la libertad esperanzada enlaza con el extremo del tiempo» ${ }^{51}$.

La esperanza mira al futuro extratemporal. También la fe. Y, asimismo, la culminación de la caridad. Si estas tres se entrelazan sin perder la dirección a dicho futuro hay que hablar de fidelidad. Esta no es, por tanto, una virtud de la voluntad, sino el sí de la persona ante dicho futuro: «más allá de cualquier decisión está la fidelidad. La fidelidad está, como la esperanza, en el futuro [...] En definitiva, se espera ser otro para el otro» ${ }^{52}$, y esto es personal, no volitivo. En ese sí fiel radica lo que Polo denomina «destinarse»: «que el destinar es ulterior al fin es manifiesto si el hombre es una segunda criatura, pues entonces mi fin no es el mundo, ni Dios como autor del mundo, sino Dios como mi creador ${ }^{53}$. Si la meta felicitaria de la persona fuese un bien último sin connotación personal, la persona humana no se destinaría. Por eso

«[...] la cuestión del destinar reside en el destinatario. Por decirlo de algún modo, al hacer el balance de todo lo que es desde la persona, el hombre se encuentra con que eso no le basta, sino que tiene que encontrar un término, que no es el término de deseo, sino el del ofrecimiento [...]. Sin correspondencia la superioridad del amor frente al deseo no tendría sentido. La esperanza se funda en la reciprocidad amorosa y se dirige a fomentarla por encima de las veleidades humanas: el hombre está autorizado a esperarla. La esperanza no es una tendencia porque se funda en el amor e intenta corresponder ${ }^{54}$.

Como se puede advertir, no estamos en el ámbito de la voluntad, sino en el del amor personal. En efecto, la voluntad, como potencia que es, quiere un bien del que carece, pues sin adaptarse a él no puede crecer según virtud. En cambio, el amor personal, como coacto del ser personal que es, no es carente, sino desbordante, y por eso oferente. Por eso reclama a una persona distinta que acepte enteramente el ofrecimiento personal. Así se entiende que, si la esperanza sobrenatural está unida a la caridad, "la esperanza cristiana es la búsqueda de aceptación y de respuesta, es decir, de encontrar al semejante ${ }^{55}$. Si la esperanza no estuvie-

\footnotetext{
$50 \quad$ Leonardo Polo, La persona humana, 75.

51 Leonardo Polo, La persona humana, 79.

52 Leonardo Polo, Lecciones de psicología clásica, 312.

53 Leonardo Polo, La esencia del hombre, 62.

54 Leonardo Polo, La esencia del hombre, 63.

55 Leonardo Polo, La esencia del hombre, 63.
} 
se vinculada a la caridad renunciaría a dar, porque el amor personal es oferente sin compensaciones. Por eso «la esperanza no reclama la autoría del otorgamiento, ni exige su reconocimiento: renuncia a que sobre ella recaiga la atención ajena, precisamente porque no renuncia a dar, y porque la insatisfacción equivale a no cansarse de dar» ${ }^{56}$.

Ahora se advierte más claramente que una persona en soledad ontológica es imposible, no solo porque «una capacidad de amar completamente solitaria, sería la tragedia absoluta ${ }^{57}$, sino también porque como la esperanza está unida a la caridad, «el término de la esperanza no es lo propio, sino lo otro» ${ }^{58}$, mejor dicho, una persona distinta.

\section{6. ¿OTRO O PERSONA?}

«Otro», se acaba de escribir. Pero otro no es denominación de persona. Tampoco es el objeto de la voluntad, el cual es el bien. Entonces, ¿qué es? Pues es la referencia del yo, pero ya se ha indicado que el yo no es la persona que se es, porque como indicaba Polo "conozco mi yo, pero no sé quién soy», pues «la fórmula "yo sé quién soy" es incorrecta, incluso ridícula. Quien soy sólo lo sabe Dios» ${ }^{59}$. El yo es el ápice de la esencia humana, no el acto de ser personal; es la puerta de entrada a la persona, o la puerta por la que se manifiesta la persona, pero no es la persona. El yo denota cierta oposición al otro, porque a lo largo de la vida los yoes adquieren tipologías distintas, las cuales son en cierto modo opuestas; en cambio, ninguna persona se opone a otra. Por ende, en sentido estricto no es conveniente designar las relaciones personales como «relaciones de oposición».

Es tomista considerar que la intención de la voluntad es «de alteridad», y este término denota otro. Pero nótese que la voluntad es tendencial respecto del bien, no respecto de otro hombre. Además, saber cómo es la intención de la voluntad implica conocimiento y la voluntad no es cognoscitiva. De modo que conocemos su intencionalidad por una instancia noética superior a ella. Se trata de la sindéresis, pues es este hábito innato el que permite conocer las potencias humanas -no solo a

\footnotetext{
56 Leonardo Polo, La esencia del hombre, 63.

57 Leonardo Polo, La esencia del hombre, 64.

58 Leonardo Polo, La esencia del hombre, 64.

59 Leonardo Polo, La persona humana, 96.
} 
la voluntad-, es decir, la naturaleza humana. Pero al conocerla advierte que la nuestra es una encarnación o matización de dicha naturaleza común, de modo que no es la humanidad de los hombres. Por eso la sindéresis está abierta a conocer a los demás en sus manifestaciones -no como personas-. Esta instancia cognoscitiva se denomina modernamente yo, y de él se dice que está abierto a los otros. Cuando la sindéresis ilumina la voluntad nota su intención de alteridad, cuyo vértice es la virtud más alta de esta facultad: la amistad. Por eso se suele describir al amigo, desde Aristóteles, como otro yo ${ }^{60}$.

Por el contrario, una voluntad curvada sobre sí misma, como la «voluntad de poder» que describe Nietzsche ${ }^{61}$, o un yo, es decir, egoísta, como el que denuncia Kierkegaard ${ }^{62}$, se afirma a fuerza de eliminar al otro. Pero eso es pura manifestación en la esencia humana de que el amor personal no se ejerce, y por tanto, de que está matando la esperanza, la cual inhiere en la libertad personal: «sin referencia al otro no hay esperanza ni amor ${ }^{63}$. Pero a diferencia de la voluntad y del yo, la referencia de la libertad personal esperanzada y del amor personal es una persona distinta: "la esperanza está en el orden del amor, exige un beneficiario o destinatario, el cual debe ser otro que el sujeto" ${ }^{64}$, distinto a la propia persona.

En cristiano la noción de otro se llama prójimo, y «esta noción significa que, si yo soy un ser capaz de amar, el otro ha de ser tal que no esté privado de esa capacidad ${ }^{65}$. Pero capaz de amar solo lo son las personas, porque amar implica aceptar y dar, y nadie salvo las personas aceptan y otorgan. Por eso, «si los otros no son personas, ¿a quién doy?» ${ }^{66}, \mathrm{y}$ ¿a quién acepto? Más aún, «¿quién lo va a aceptar? El ámbito de resonancia de la capacidad de dar ha de ser también personal; de otro modo

60 Cfr. Leonardo Polo, "La amistad en Aristóteles", Anuario Filosófico 32 (1999): 477-485.

61 «La voluntad de poder ha de renunciar a la esperanza, porque ésta admite el otro... En Nietzsche no hay esperanza al suprimir la posibilidad de la síntesis por eliminación de lo otro». Leonardo Polo, Antropología trascendental, 417.

62 Cfr. Leonardo Polo, La esencia del hombre, 75 ss.

63 Cfr. Leonardo Polo, La esencia del hombre, 76. En otro lugar escribe: "la esperanza... lo es respecto de otro". Obras Completas, vol. 11, Lecciones de ética (Pamplona: Eunsa, 2018), 76.

64 Leonardo Polo, La esencia del hombre, 78.

65 Leonardo Polo, Epistemología, 61.

66 Leonardo Polo, Epistemología, 61. 
es absurda. ¿Quién responde a la iniciativa esperanzada? El problema clave es la correspondencia ${ }^{67}$. En rigor, si no llegásemos a ser enteramente aceptados, acabaríamos sin sentido, y nuestra presente vida habría sido absurda.

Se ha indicado que el ser humano en esta vida es esperanza. Por eso la vida histórica humana es esperanzada. La esperanza mira al futuro meta-histórico. En consecuencia, la elevación del ser humano por la virtud teologal de la esperanza caracteriza a la Iglesia en este mundo ${ }^{68}$.

\section{LA ESPERANZA, A GRANDES RASGOS, EN LA HISTORIA DE LA HUMANIDAD}

Se puede decir que, desde el inicio de la humanidad, inmediatamente tras el pecado original de Adán y Eva, la humanidad está a la espera del Salvador. Pero ese momento, y los sucesivos, todavía los tenemos perdidos en la noche de los tiempos. Lo que es claro es que en la historia de las civilizaciones existe un pueblo que no se entiende sin la esperanza sobrenatural, el judío: «en el pueblo judío, que es el pueblo de la promesa, la virtud central era la esperanza ${ }^{69}$. En efecto, este pueblo está volcado a la futura figura del Mesías, y en eso se distingue de las demás civilizaciones antiguas. Así, por ejemplo, «la orientación del Antiguo Testamento es muy distinta de la hindú, como se ve el libro de Job. Job no es abatido por la acometida del dolor; su personalidad no queda sumida en una penosa interrogación sin esperanza de respuesta, es decir, dirigida al vacío ${ }^{70}$. Con todo, el pueblo judío cometió muchos errores a lo largo de su recorrido por poner la esperanza en realidades que no son

\footnotetext{
67 Leonardo Polo, Epistemología, 118.

68 Sin embargo, Polo piensa que a nosotros nos caracteriza más la fe y la Iglesia purgante la esperanza: "Una de las diferencias entre estos tres estados de la Iglesia puede cifrarse en la virtud infusa prevalente en cada una de ellas. En la celeste desaparecen la fe y la esperanza y permanece únicamente la caridad. En la purgante, la virtud principal es la esperanza segura. En la militante se dan las tres, y tiene especial importancia la fe. Ni siquiera la militante es solamente una sociedad. Considerada como sociedad es una jerarquía en que los superiores se deben a los inferiores». Leonardo Polo, Epistemología, 277.

${ }_{69}$ Leonardo Polo, Quién es el hombre, 130. En otro lugar insiste en este punto: «Sin duda la esperanza es el nervio del Antiguo Testamento». La originalidad, 307.

70 Leonardo Polo, Epistemología, 266.
} 
mesiánicas. También por eso «en la Revelación veterotestamentaria la corrección de la esperanza es un motivo central $\gg^{71}$. Y aunque dicha promesa todavía se guarda hoy parcialmente en el pueblo judío, requiere asimismo corrección, pues injustificadamente no da un voto de confianza a Cristo como Mesías: «la esperanza de Israel se mantiene en la actualidad por lo menos en una parte del pueblo. Los peligros que la acechan son debidos a no aceptar que Cristo es el Mesías» ${ }^{72}$. Por su parte,

«[...] la esperanza se intensifica mucho en el Nuevo Testamento precisamente porque hay una diferencia entre la primera venida y la segunda (de Cristo). Pero la esperanza es el alma del primer testamento, mal llamado Antiguo porque es el primero. Toda la historia de Israel es una historia de esperanza, por eso el Antiguo Testamento no es mítico porque lo mítico comporta la idea de tiempo cíclico y la esperanza comporta la idea de tiempo abierto, el futuro. Es futurización, está por, todavía no; eso es la esperanza ${ }^{73}$.

En efecto, «el cristianismo ha puesto sobre el tapete y ha incorporado a la historia de una manera muy neta la esperanza $\rangle^{74}$. El pueblo cristiano ha conocido al Mesías, pero sigue a la espera de su segunda venida, de modo que también a este pueblo caracteriza la esperanza. Téngase en cuenta que la última palabra de la revelación del «Nuevo Testamento termina también con el Maran-ata ${ }^{75}$, ven Señor Jesús. Eso no indica que el cristiano, en espera de la parusía, se cruce de brazos en esta vida, sino que orienta y anima todo su quehacer en orden a alcanzar aquélla. Por eso «puede decirse que la esperanza es la virtud infusa más cercana al transcurso de la vida. El cristiano mira desde ella la problemática surgida de su existencia espacio-temporal, entroncándola con la segunda venida de Cristo» ${ }^{76}$.

Dentro de la filosofía se pueden distinguir dos fases en este punto: la clásica, en la que se mantiene la esperanza; y la moderna, en la que renuncia a ella. En efecto, Polo escribió que «los pensadores clásicos son actuales, no unas fases pasadas a partir de las cuales hayamos construido otras nuevas, porque poseen una esperanza cierta que fue rechazada

\footnotetext{
71 Leonardo Polo, La originalidad, 307.

72 Leonardo Polo, Epistemología, 215, nota 14.

73 Leonardo Polo, Conversaciones en Torreblanca, 191.

74 Leonardo Polo, Filosofía y economía, 238.

75 Leonardo Polo, Nietzsche, 225, nota 51.

76 Leonardo Polo, La persona humana, 67.
} 
en los inicios de la era histórica a cuyo final hoy asistimos» ${ }^{77}$. Sí, «la Edad Moderna [...] se inaugura con una drástica restricción de la esperanza que conlleva la degradación de lo óptimo a la condición de utopía ${ }^{78}$. En efecto, tras esa renuncia, en la filosofía moderna se introdujo un sentido de la esperanza que no es sobrenatural, sino terreno: «la idea de progreso indefinido, vinculada a estimulantes promesas, es en cierto modo una versión secularizada de la esperanza. La esperanza es uno de los grandes ingredientes de la historia occidental, sobre todo a partir de la incidencia del cristianismo ${ }^{79}$, y se olvida cuando el cristianismo entra en pérdida y no vivifica la sociedad.

La negación moderna de la esperanza tuvo su clímax con Hegel, el gran demoledor de la misma: «Hegel detesta la esperanza, quiere liberarse de ella mediante el estricto logro en presente del resultado Absoluto. Pero además la esperanza de Marx es simplemente terrenal y, por tanto, utópica ${ }^{80}$. En efecto, la futurología marxista es una salida en falso, anónima e impersonal, de la esperanza, como lo es la «mano invisible» de Adam Smith. Las esperanzas de estas ideologías son ilusorias y «no se puede pretender mejorar al hombre alentando una esperanza ilusoria ${ }^{81}$. Es obvio que también la filosofía de Nietzsche es contraria a la esperanza, porque, en rigor, es imposibilitada por el eterno retorno. Tales derroteros surcaron la filosofía moderna hasta que «Kierkegaard repone la esperanza como curación efectiva de la desesperación; Freud no, lo que significa que la desesperación no es relativa a ninguna esperanza: nadie va a venir, ninguna iniciativa saldrá al encuentro» ${ }^{82}$, y muchos de los filósofos posteriores tampoco, pues es claro, por ejemplo, que dentro del existencialismo la esperanza estuvo encapotada. Polo nos pregunta:

«¿Y cómo andamos de esperanza? La pregunta es inevitable porque sin esperanza nos paramos. ¿Dónde ponemos la meta o la cima de nuestra vida? ¿Demasiado cerca? Seguramente será un objetivo para

\footnotetext{
77 Leonardo Polo, Obras Completas, vol. 10, Presente y futuro del hombre (Pamplona: Eunsa, 2015), 301.

78 Leonardo Polo, Presente, 313.

79 Leonardo Polo, Obras Completas, vol. 12, Introducción a la filosofía (Pamplona: Eunsa, 2015), 99.

80 Leonardo Polo, Obras Completas, vol. 8, Hegel y el posthegelianismo (Pamplona: Eunsa, 2018), 270.

81 Leonardo Polo, Ética, 93.

82 Leonardo Polo, Obras Completas, vol. 21, Curso de psicología general (Pamplona: Eunsa, 2018), 190.
} 
dentro de una hora; pero no es una gran esperanza. Después de la cena, ¿qué podemos esperar? Quizá una película. Péguy, el gran poeta francés, escribió un poema sobre la esperanza. Para Péguy, la esperanza es el bastón del caminante: un bastón de caña, flexible, que ayuda a andar. La esperanza es el bastón del camino; tiene que ver con los grandes proyectos. En otro caso acontece más bien lo que decía Dante: en mitad del camino de nuestra vida me encontré en una selva obscura, porque la vía derecha se había perdido, había desaparecido. Sin la esperanza uno se encuentra perdido en la maraña de la vida: no sabe qué hacer» ${ }^{83}$.

Puede que hoy no falten proyectos, pero suelen ser de corto plazo y alcance, y no precisamente propios de la esperanza sobrenatural, aunque -como en todas las épocas de crisis, y por misericordia divina ${ }^{84}$, que es la superior ayuda ${ }^{85}$ - siempre hay notables excepciones. Pero, por lo general, "en nuestra época hay una fuerte pérdida de esperanza, y sin embargo, hoy más que nunca hay proyectos posibles» ${ }^{86}$.

Polo ve la causa de esta carencia actual de esperanza en el fracaso de la mentalidad moderna del progreso indefinido, que pareció tocar fondo a mediados del s. XX: "yo creo que el origen del postmodernismo está en ese fracaso de todas las esperanzas puestas en el progreso que acabó en una guerra espantosa en la que seguramente hubo más muertos que nunca. Fue una especie de estrago en toda Europa ${ }^{87}$. Sin embargo, tras esa enorme tragedia se han dado muchas ayudas que han permitido restaurar la unión y el orden social en el viejo continente. Sin embargo, en las últimas décadas tal unión se resquebraja por diversas partes seguramente debido al individualismo.

En efecto, nuestra sociedad europea -que exporta su actitud a los países que caen bajo su ámbito de influencia- es tremendamente individualista, y el individualismo es la destrucción de la esperanza natural (y, por ende, de la sobrenatural), porque de los nueve puntos con que Polo la describe, el individualista solo afirmará uno: el propio sujeto. En especial

83 Leonardo Polo, Ética, 154.

84 «Conviene señalar la ceñida vinculación entre la justicia divina y su misericordia, sin la cual la esperanza humana perdería vigor». Leonardo Polo, Epistemología, 309.

85 «A través de la mayor debilidad se abalanzó el poder divino, que rompe el carácter crispado de la miseria humana y la abre a la esperanza». Leonardo Polo, Epistemología, 296.

86 Leonardo Polo, Ética, 154-155.

87 Leonardo Polo, Conversaciones en Torreblanca, 215. 
rechazará que exista un quién que encargue la tarea y que exista algún beneficiario al margen de sí mismo:

«El nihilismo moderno consiste en la restricción de elementos a que ha sido sometida la tarea esperanzada por parte de la ideología [...] ¿Qué dice el individualista de la esperanza? Mantiene, desde luego, que el sujeto de la tarea soy yo. ¿En qué consiste la tarea? En la voluntad del poder, o más modestamente en el éxito (la noción de éxito es muy confusa). ¿Y el beneficiario? El individualista dice: yo. He aquí una restricción grave. ¿Recursos? Nada más que los míos. ¿Adversarios? El individualista dice: todos los demás. ¿Quién encarga la tarea? Respuesta: nadie» ${ }^{88}$.

Ahora bien, quien niega a las demás personas como término de su referencia, acaba negando su referencia personal, lo cual equivale a decir que niega su ser personal, y a fuerza de negarlo este se puede perder enteramente. Por eso, cerrarse a la esperanza es abrirse a la nada. En consecuencia, el individualista es nihilista: «el individualista es un ser peninsular, que se ha rodeado de nadie por todas partes menos por una: él mismo. Esto es nihilismo ${ }^{89}$. Advertir que el individualismo sea nihilismo es otro modo de notar que el individualismo es la negación de la persona, pues esta es apertura, relación constitutiva, coexistencia-con. También el ateo es, al final, nihilista. No puede ser de otro modo, porque negar a Dios comporta negar el propio ser personal humano abierto a él, por tanto, negar la apertura constitutiva del ser personal y, por ende, negarse. Si niega su propio ser personal, ¿qué valor puede tener para él este mundo? Desde luego, un valor muy limitado y relativo.

Individualismo y ateísmo no son naturales sino adquiridos forzosamente. Su causa es la soberbia ${ }^{90}$ a nivel personal, y el egoísmo ${ }^{91}$ a nivel esencial. Su fruto, la soledad. Su poso, la tristeza, un afecto negativo del espíritu. Además de esas dos causas del individualismo -una en el acto de ser personal y otra en la esencia humana- la tercera está en la natura-

\footnotetext{
88 Leonardo Polo, La esencia del hombre, 79.

89 Leonardo Polo, La esencia del hombre, 79.

90 "El egoísmo y la soberbia agostan el ser donal". Leonardo Polo, Epistemología, 193.

91 Por eso, «el cristiano, para estar alegre necesita corregirse, porque de otra manera no puede mantener su esperanza ontológica y puede caer en el egoísmo. Ceder a ello es un solipsismo incompatible con el carácter coexistencial de su persona». Leonardo Polo, Epistemología, 321.
} 
leza orgánica humana y radica en la búsqueda del placer, el cual siempre se da en presente. Un ejemplo que Polo pone al respecto es el de Esaú, que cambió su futuro por un plato de lentejas ${ }^{92}$.

\section{NEGACIONES DE LA ESPERANZA}

Niega o desconoce al ser humano quien dice que su centro radica en el pasado temporal o en el momento actual histórico. Del primer estilo es el mito (también el tradicionalismo): «el mito es la interpretación de cualquier presente como tardío ${ }^{93}$. Del segundo, por ejemplo, el pensamiento de Hegel. Este es el mayor presencialista que ha habido, del que Polo pone en su boca el siguiente comentario desilusionado al final de sus días:

«[...] "hasta el momento yo creía que había superado la esperanza (que estaba más allá de la esperanza); hoy tengo que confesar que todo sigue igual". Es decir, la historia no ha culminado. Hegel cree -sigue indicando Polo- que la esperanza es una debilidad. Es un filósofo del Absoluto y, por tanto, la esperanza, como lo potencial en el orden del amor supremo, es para Hegel simple provisionalidad y quiere verse liberado de ella, situado en lo definitivo. Pero es claro que esa falta de apreciación de la esperanza solamente puede ocurrir si se ignora la libertad positiva, si no se sabe que la libertad no es simplemente estar libre de, sino estar en disposición para $»^{94}$.

Lo que precede indica que la libertad no culmina, no alcanza su meta, en esta vida, lo cual denota que es creciente y -como se ha reiterado- es elevada por la esperanza: «en el hombre la libertad no es un trascendental fijo, sino que sólo se mantiene en tanto que crece apuntando a su fin. La aceptación divina de ese crecimiento justifica la esperanza» ${ }^{95}$.

92 «El hombre sin esperanza sucumbe ante la perspectiva de un gozo inmediato, como es el caso de Esaú, que por esta razón fue excluido del favor divino». Leonardo Polo, Epistemología, 266.

93 Leonardo Polo, La persona humana, 72.

94 Leonardo Polo, Obras Completas, vol. 14, Nominalismo, idealismo y realismo (Pamplona: Eunsa, 2015), 90.

95 Leonardo Polo, Epistemología, 321. 
Al final, tanto el hombre mítico (o tradicionalista) como el presencialista se vuelven pesimistas ${ }^{96}$, porque no está diseñada la persona humana para culminar en el tiempo histórico. Si la persona humana está hecha para alcanzar a Dios, solo se culmina cuando se le alcanza definitivamente, pero si bien Dios actúa en la historia, su ser está fuera de la historia, ya que es eterno, o si se quiere, la eternidad es Dios. En la historia no hay nada definitivo, porque lo distintivo de ella es que pasa ${ }^{97}$, transcurre y no culmina. Con todo, ya que todo hombre es esperanza y la historia depende del ser humano, cabe decir que la historia debe mirar a la escatología ${ }^{98}$.

Lo definitivo para el hombre solo es post mortem. Por eso, la esperanza sobrenatural, que es distintiva de esta situación, pese a ser un don divino, tampoco es definitiva y está llamada a desaparecer: "Dice San Pablo que de estos tres desaparecerán la fe, la esperanza; sólo quedará la caridad. ¿Por qué? Si hay visión, la fe no hace falta; si se ha alcanzado a Dios desaparece la esperanza y (si no se ha alcanzado, también). Entonces quedan la caridad y la visión ${ }^{99}$. Si no se ha alcanzado a Dios después también desaparece la esperanza porque ya no se le puede alcanzar.

El pesimismo del hombre mítico (y del tradicionalista) y del presencialista es tan agudo -afecta a la intimidad humana- que es mejor designarlo como tristeza: «la tristitia es el horizonte de la esperanza encapotado. La tristeza del espíritu, dice Tomás de Aquino, es el dolor más agudo de todos $»^{100}$. Esta actitud lleva en la práctica a permanecer de brazos caídos, es decir, a la inactividad, porque si se considera que haga lo que haga, el ser humano no mejora radicalmente, ni puede culminar, ¿para qué actuar? «En la tristeza la falta de esperanza se anticipa a la acción e impide que se ponga en marcha» ${ }^{101}$.

96 «Al final de su vida, las dudas sobre la aptitud de su tiempo para la culminación del espíritu, reponen en Hegel la esperanza con cierto aire de aburrimiento, como acertadamente captó Kierkegaard». Leonardo Polo, Antropología trascendental, 420 , nota 81.

97 «Esta vida no es la más alta para el viviente, que espera una vida más plena después de la muerte». Leonardo Polo, Antropología trascendental, 356.

98 «En tanto que la esperanza es propia de todo hombre, se puede decir que la historia tiene un sentido escatológico, o sea, que ella misma también terminará. Desde cualquier otro punto de vista la historia humana no termina». Leonardo Polo, Epistemología, 321.

99 Leonardo Polo, Antropología de la acción directiva (Madrid: Aedos, 1997), 116 , nota 1 .

100 Leonardo Polo, Presente y futuro del hombre, 248.

101 Leonardo Polo, La persona humana, 61. 
«Existen otros dos tipos humanos incapaces de vivir con esperanza -escribe Polo-: los dubitantes y los inconscientes. El dubitante es el que hecha cuentas sobre los recursos de que dispone olvidando que se pueden incrementar, y aprecia en demasía las dificultades. Es el que se deja asustar por el dolor y no sabe acudir a la ayuda o a la cooperación. Por su parte, el inconsciente es aquel que se atiene a la frase de Foch: primero se lanza uno, después se mira. Mejor aún, el inconsciente lo es para todo menos para el rencor. La tarea esperanzada es incompatible con el rencor porque el rencor es hijo del miedo. Si el miedo se introduce en el esperar, éste es sustituido por el sentimiento de urgencia o por el exceso de cálculo» ${ }^{102}$.

La duda es falta de confianza, y esta, en lo sobrenatural, deriva de la falta de fe, que es la elevación del intelecto personal (no de la razón como potencia). La inconsciencia deriva de la falta de dicho intelecto, pero la ausencia de este no es nativa, sino adquirida culpablemente.

Entre los ejemplos de desesperanza, Polo pone también al fideísmo: «el fideísmo es una modalidad de desesperanza. A partir de él, el pensamiento se dedica a otras cosas (o trata de apoderarse de la fe. Es lo que acontece en el peculiar gnosticismo que es el idealismo alemán)» ${ }^{103}$. De fideísmo está llena la tradición de autores protestantes. Tampoco algunos escritores católicos son inmunes a él. En efecto, si se mantiene que hay que jubilar la razón en orden a penetrar en el contenido revelado porque se supone que este es absurdo, desde ese momento la razón se encamina por unos derroteros que están al margen y son contrarios a los de la fe, de modo que o bien la suplanta o bien la engulle. "Con todo, la vacilación fideísta no arruina por completo la apertura donal que el hombre encuentra en sí al afianzarse su capacidad de querer. Esta apertura se concentra en el concepto de esperanza ${ }^{104}$.

Negaciones de la esperanza son, asimismo, el cambiar el valor ante el riesgo por la cobardía o por la temeridad. Y otra negación es la que supone enfrentar el riesgo como el revolucionario radical que llega a ser terrorista, pues las características de este son contrarias a la esperanza, porque aunque pueda asumir riesgos: 1) no cuenta con los demás, sino que va contra ellos; 2 ) en sentido propio no desempeña una tarea, porque destruir es fácil; 3) su vida es negativa, mientras que la esperanza es

\footnotetext{
102 Leonardo Polo, “La esperanza”, 161.

103 Leonardo Polo, Filosofía y economía, 237.

104 Leonardo Polo, Filosofía y economía, 238.
} 
positiva; 4) no congrega o convoca porque produce cínicos ${ }^{105}$ cuya actitud es disolvente.

Es clásico por parte de la Iglesia católica admitir dos defectos graves contra de la esperanza: la desesperación y la presunción. Si el primero suele afectar a personas que no son o no viven como cristianos, porque «la Iglesia es el intérprete más autorizado de las esperanzas del hombre -dado que la Iglesia se atreve valientemente a esperar la destinación del hombre al Bien infinito-»106, aunque «poca gente vive la locura diabólica o desesperación radical» ${ }^{107}$, el segundo afecta a algunos sectores cristianos $^{108}$. Pero esta segunda actitud es una deformación de la verdadera esperanza cristiana, la cual «no es petulante, porque se basa en la misericordia de Dios» ${ }^{109}$.

\section{CONCLUSIONES}

Como colofón a este estudio sobre la esperanza sobrenatural según el pensamiento de Leonardo Polo, podemos plasmar las tres siguientes inferencias que formulamos de modo breve:

$1 .^{a}$ La esperanza sobrenatural es el don divino que eleva uno de los trascendentales del acto de ser personal humano, a saber, la coexistencia libre. Por tanto, no inhiere directamente en la esencia humana (en el yo o en las facultades inmateriales que este activa: la inteligencia y la voluntad).

2. ${ }^{a}$ La esperanza sobrenatural requiere de la fe y de la caridad sobrenaturales; por eso no se da aislada de ellas.

3. ${ }^{\mathrm{a}}$ La esperanza sobrenatural es susceptible de incremento por don divino, orientada siempre al futuro metahistórico hasta la culminación del destino humano en el Dios pluripersonal revelado.

105 Leonardo Polo, La esencia del hombre, 73.

106 Leonardo Polo, Presente y futuro del hombre, 317.

107 Leonardo Polo, "La esencia del hombre", 73.

108 «El cristiano puede sufrir la tentación de absolutizar la esperanza. Y, así, ciertos sectores eclesiásticos vierten en la acción todas las virtualidades de la fe. Se "apoderan" del mensaje evangélico y, al trasladarlo al plano de las realizaciones prácticas, lo ofrecen como un panorama de necesidad intramundana». Leonardo Polo, La persona humana, 83.

109 Leonardo Polo, La persona humana, 64. 


\section{REFERENCIAS}

Polo, Leonardo. "La esperanza". Scripta Theologica 30 (1998): 157-164.

—. "La amistad en Aristóteles". Anuario Filosófico 32 (1999): 477-485.

- La persona como centro de la enfermería. Pro manuscripto.

-. El hombre en la historia. Cuadernos de Anuario Filosófico 207. Pamplona: Servicio de Publicaciones de la Universidad de Navarra, 2008.

-. Obras Completas. Vol. 8, Hegel y el posthegelianismo. Pamplona: Eunsa, 2018.

-. Obras Completas. Vol. 10, Presente y futuro del hombre. Pamplona: Eunsa, 2015.

—. Obras Completas. Vol. 10, Quién es el hombre. Pamplona: Eunsa, 2015.

-. Obras Completas. Vol. 11, Ética: hacia una versión moderna de temas clásicos. Pamplona: Eunsa, 2018.

—. Obras Completas. Vol. 11, Lecciones de ética. Pamplona: Eunsa, 2018.

-. Obras Completas. Vol. 12, Introducción a la filosofía. Pamplona: Eunsa, 2015.

-. Obras Completas. Vol. 13, La persona humana y su crecimiento. Pamplona: Eunsa, 2015.

-. Obras Completas. Vol. 13, La originalidad de la concepción cristiana de la existencia. Pamplona: Eunsa, 2015.

-. Obras Completas. Vol. 14, Nominalismo, idealismo y realismo. Pamplona: Eunsa, 2014.

-. Obras Completas. Vol. 15, Antropología trascendental. Pamplona: Eunsa, 2015.

-. Obras Completas. Vol. 17, Nietzsche como pensador de dualidades. Pamplona: Eunsa, 2018.

-. Obras Completas. Vol. 19, Persona y libertad. Pamplona: Eunsa 2017.

-. Obras Completas. Vol. 21, Curso de psicología general. Pamplona: Eunsa, 2019.

-. Obras Completas. Vol. 22, Lecciones de psicología clásica. Pamplona: Eunsa, 2015.

-. Obras Completas. Vol. 23, La esencia del hombre. Pamplona: Eunsa, 2015.

-. Obras Completas, vol. 25, Filosofía y economía. Pamplona: Eunsa, 2015.

-. Obras Completas. Vol. 27, Epistemología, creación y divinidad. Pamplona: Eunsa, 2015. 
